\title{
CRITERIOS DE ORDEN DE LA CIUDAD INFORMAL La morfología de asentamiento informal de Busan, Corea del Sur
}

\author{
Meehwa Cho \\ Universidad: ETSAB-UPC \\ Director de la tesina: Joaquín Sabaté Bel \\ 3cn@meehwacho.zz.mu
}

\section{RESUMEN}

La aparición de los asentamientos informales es un fenómeno global en ciudades con un fuerte crecimiento demográfico. En el caso de Busan, la segunda ciudad de Corea del Sur, experimentó una explosión demográfica en tres ocasiones: colonización, guerra e industrialización. El área urbana se expandió, sin dar tiempo a planificarla, absorbiendo los límites geográficos como las montañas y los ríos, justamente donde aparecen asentamientos informales que se denominan barrios de luna, en Corea. Aunque estos asentamientos arrancaban de una vivienda precaria, al final, muchos de ellos con el transcurso de las décadas se urbanizaron a su manera; con lo cual, debe haber un orden o un código común que compartan sus habitantes. El estudio se enfoca en los elementos físicos que condicionan su crecimiento y su transformación. Una vez se entiende su morfología, la diferencia entre lo formal y lo informal estaría solo en la facilidad de percibir su orden.

Palabras clave: asentamiento informal, morfología urbana, orden geográfico

\begin{abstract}
The growth of informal settlements is a global phenomenon in cities with a population explosion. In the case of Busan, the second city of South Korea, there was rapid population growths on three occasions: colonization, war and industrialization. The urban area expanded, without time to plan, absorbing the geographical borders like the mountains and the rivers, where they appear informal settlements that are denominated "moon town" in Korea. Although these dwellings started as a shanty town many of them urbanized in their own way over the course of the decades. Thus, there must be their own logic or code that shared by the inhabitants. The study focuses on the physical elements that condition its growth and transformation. Once its morphology is understood, the difference between the formal and the informal would be only in the easiness of perceiving its order.
\end{abstract}

Key words: informal settlement, urban morphology, geographic order 


\section{URBANIZACIÓN ACELERADA Y ASENTAMIENTOS INFORMALES Contextualización de Busan en la situación internacional}

El objetivo de este capítulo es localizar el crecimiento urbano de Busan dentro del contexto internacional. Debido a las particularidades históricas de cada país y las características de cada ciudad, es difícil dar una explicación genérica acerca del surgimiento de los asentamientos informales. Sin embargo, se pueden intentar presentar las principales tendencias y las características comunes, relacionando el proceso de crecimiento urbano (índices de crecimiento urbano, datos demográficos, desarrollo económico y valor industrial, etc.) con los momentos decisivos de diferentes ciudades.

Estos asentamientos existen en muchas ciudades del mundo con otros nombres, por ejemplo, slum, ghetto, favela (Brasil), pobla (Chile), ciudad perdida, barrio bajo (Méjico), pueblo joven, barriada, asentamiento humano (Perú), campong (Indonesia), barrio de luna (Corea del Sur), etc. Aunque hoy en día lo conocen como un fenómeno del hemisferio meridional, la aparición de asentamientos informales es un fenómeno común en todo el mundo, en las ciudades que sufren de un crecimiento explosivo, tanto en el hemisferio meridional como en el septentrional, no sólo en el siglo XX, sino también en el siglo XIX.

Sin embargo, "la dinámica de urbanización del siglo XX resume y confunde al mismo tiempo los precedentes del siglo XIX del Europa y Norteamérica" (Davis, 2007:24). La mayoría de los países de Asia se independizaron en los años cuarenta o más tarde. De este modo, en las ciudades de Asia la fuerte industrialización se produce un siglo más tarde que en las primeras ciudades industriales. En cambio, los países de América Latina se emancipan en las primeras décadas de siglo XIX. Especialmente, Brasil y México se anticipan bastante al proceso de industrialización comparados incluso con los países del mismo continente. Algunas de estas ciudades que experimentan fuerte crecimiento en el siglo XX, antes de la llegada de la industrialización, ya estaban pobladas con más de un millón de habitantes, cifra que supera la máxima población que han tenido algunas ciudades europeas durante todo su proceso de industrialización. Así, el crecimiento del siglo XX se produce a una escala mucho mayor y con una velocidad mucho más acelerada que en el siglo XIX, sin dar tiempo a planificar.

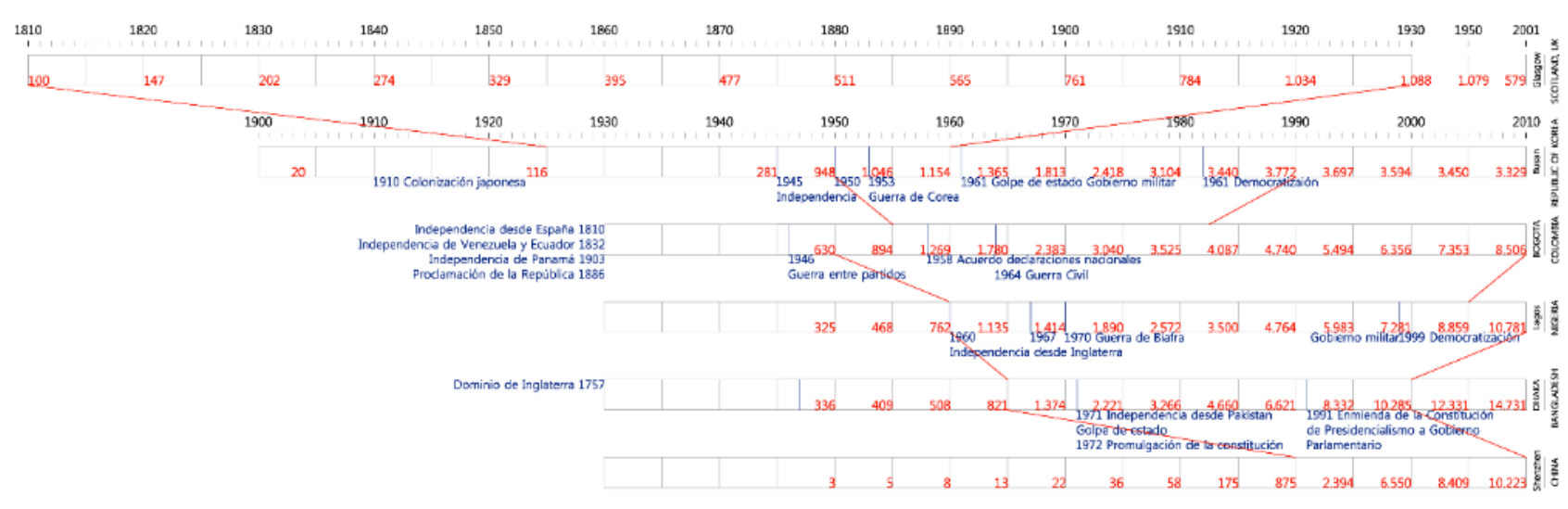

Aceleración del crecimiento demográfico

El aumento de la población que ha tenido Glasgow durante 120 años entre 1810 y 1930 , en Busan se dio solo en 35 años entre 1925 y 1960. El que se dio en 40 años de Busan, en Bogotá se ha dado en menos de 30 años.

En el caso de Lagos y Dhaka el crecimiento es aún mayor y en el caso de Shenzhen es extremo.

Elaboración propia a partir de datos del ONU

De hecho, muchas ciudades industriales y post-coloniales, tienen un desarrollo urbano que se caracteriza por ser caótico y confuso, con situaciones contradictorias entre diferentes patrones de la ciudad original, de la ciudad colonial y de la ciudad industrial. Tal es el caso de Busan. La dinámica demográfica de Busan es más parecida a la de algunas ciudades de Latinoamérica que a la de ciudades del mismo continente, sobre todo a Caracas (Venezuela), Lima (Perú) y Medellín (Colombia). No es casualidad que las ciudades con una dinámica similar a Busan también tengan una forma física similar aparentemente. La expansión improvisada absorbe toda la discontinuidad y la disparidad espacial, incluso los límites geográficos que antiguamente señalaban el borde de la ciudad, como las montañas y los ríos. Justamente en aquellos lugares conflictivos aparecen asentamientos informales ocupando una parte importante de la ciudad como en dichos casos. De 
esta manera, aquellas ciudades tienen dentro de ellas una parte irregular, que recibió residentes antes de disponer de suficiente construcción urbana, como una ciudad dual. En las fotos se puede observar que Busan, Caracas, Medellín y Lima tienen un tejido reticular y homogéneo por el nivel bajo, en el terreno plano; pero pierden este tejido al llegar al nivel alto, en las laderas de las montañas.

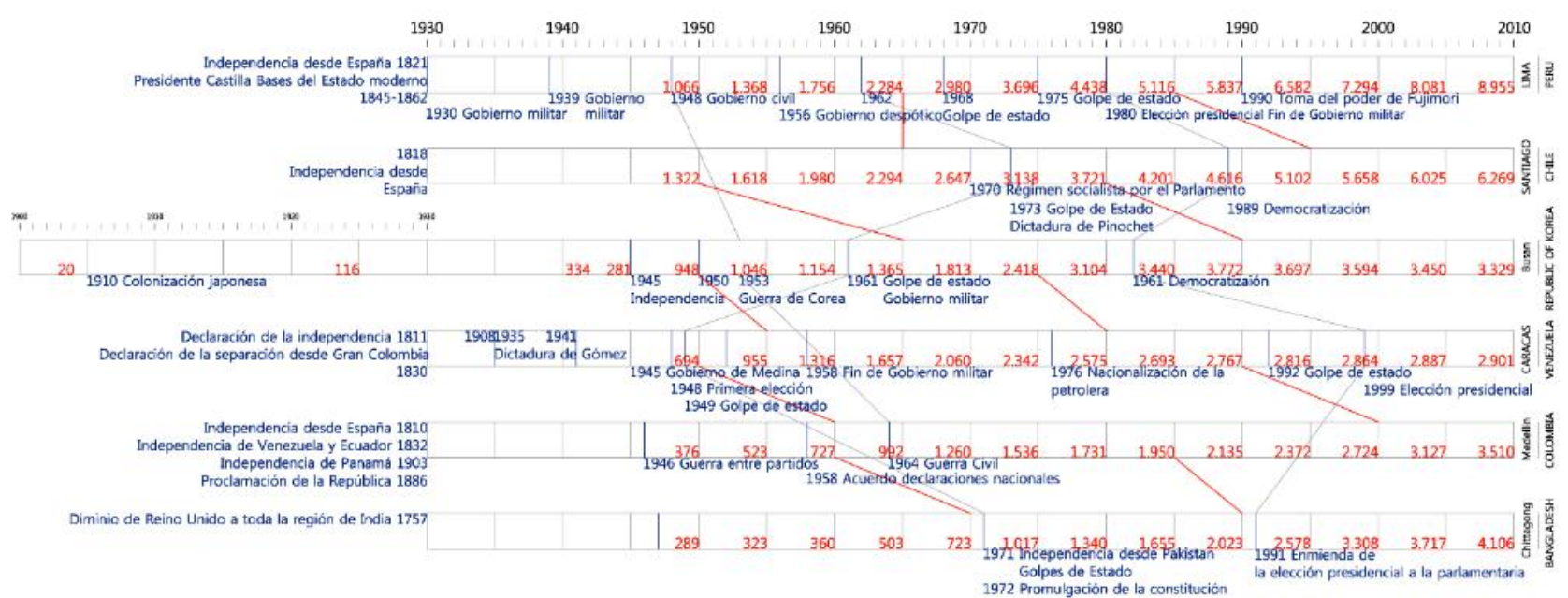

Ciudades de dinámica similares de crecimiento demográfico

Algunas ciudades de Latino América tienen una dinámica similar a la de Busan, sobre todo Caracas y Medellín. Elaboración propia a partir de datos del ONU

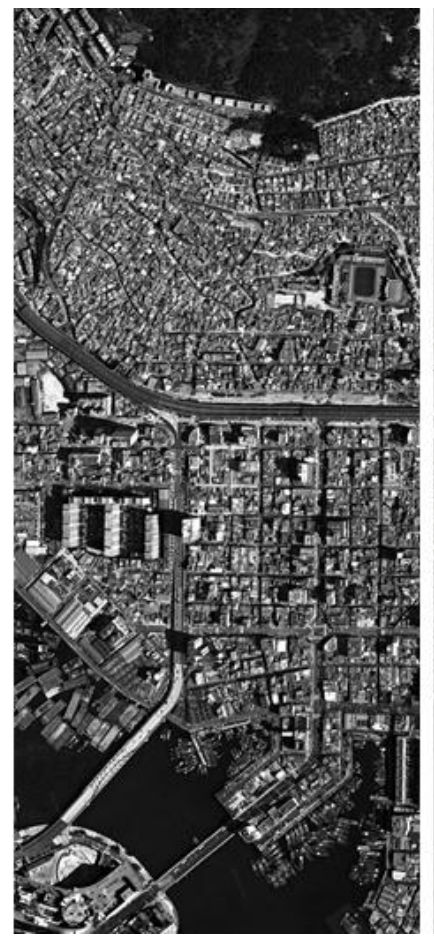

Busan, Caracas, Medellín, Lima

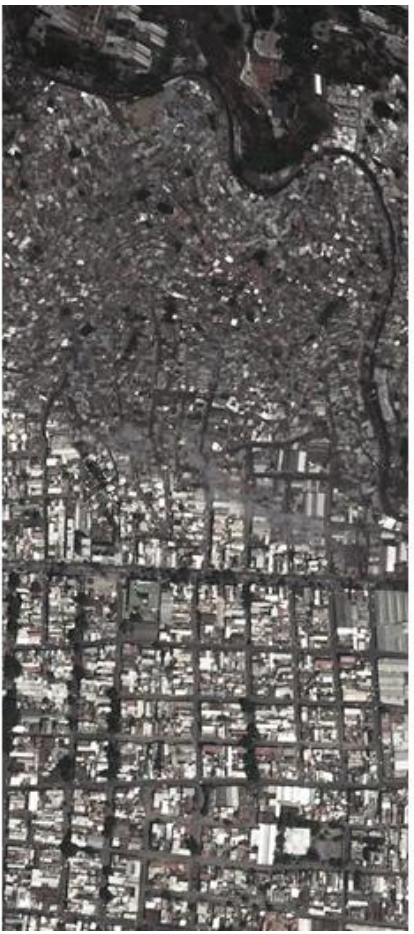

No es casualidad que las ciudades de dinámica similar a Busan también tienen una forma física similar aparentemente. (map.naver.com, 2016, Google earth, 2016)

Los tejidos en la parte alta en su comienzo eran "asentamientos" sin calles ni plazas como sus nombres acuñados, que se asocian a ser ilegales, irregulares, degradados, precarios, marginales, exclusivos, y estar en una localización complicada. Aunque estos asentamientos arrancan de viviendas auto-construidas con técnicas y materiales precarios, al final muchos de ellos, con el transcurso de las décadas, han vivido de varios procesos de transformación consiguiendo equipar condiciones de "ciudad" con servicios básicos. Por 
ello, debe haber un orden o un código común que comparten los habitantes del asentamiento que refleja su organización económica, social y sus estructuras políticas, tal es su morfología urbana.

En "Las formas del crecimiento", Manuel de Solà-Morales (1997) explica los procesos de crecimiento urbano según la secuencia de Parcelación, Urbanización y Edificación. Según dicha clasificación, los asentamientos informales serían "Urbanización Marginal" y "Barraca", que crecen sin urbanización ni control. Pero esta clasificación puede ser solo la definición del inicio de un proceso que puede tardar más tiempo para cumplir la construcción posteriormente. El mismo autor implica las posibilidades de más variedades con su propuesta del crecimiento urbano en combinación con dichos procesos en las distintas tipologías morfológicas de crecimiento.

"Estas tres operaciones (Parcelación, Urbanización y Edificación) no son actos simultáneos ni encadenados siempre de igual manera. Al contrario, de sus múltiples formas de combinarse en el tiempo y en el espacio, se origina riqueza morfológica de las ciudades. Tanto mayor, cuanto más variadas sean las formas de esa combinatoria" (Manuel de Solà-Morales, 1997).

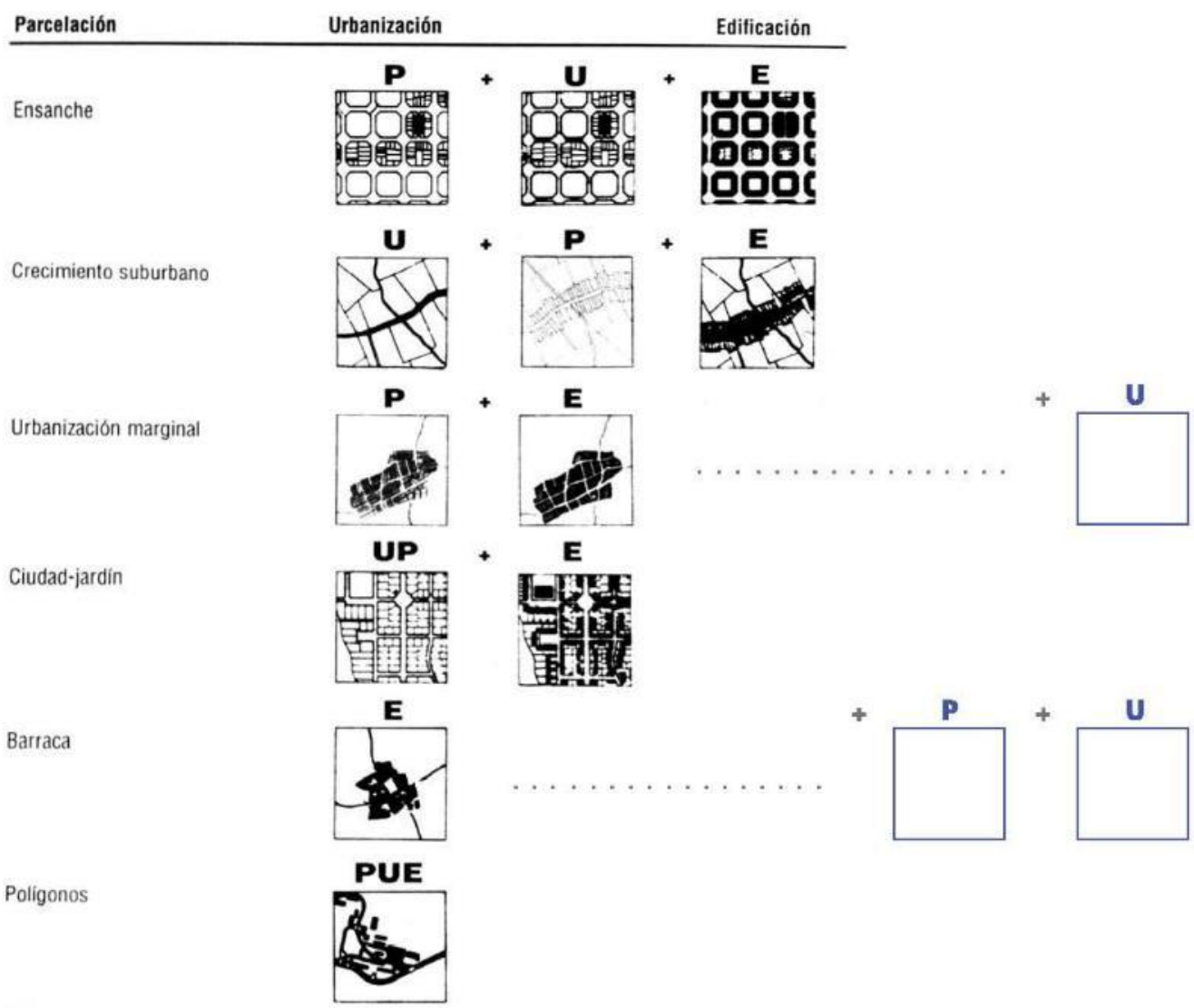

Las formas de crecimiento urbano

Los asentamientos informales se transforman también consolidando su tejido y urbanizando de los servicios básicos poco a poco a su manera. En adelante, nos queda una enorme diversidad de crecimientos y transformaciones de barracas para conocer.

Redroducción propia

de trabajo orgianl de Manuel de Solà-Morales i Rubió

\section{FORMACIÓN DE LA CIUDAD INFORMAL DE BUSAN Tres períodos de concentración demográfica}

Este capítulo se ocupa de la historia de crecimiento de la ciudad Busan enfocando en tres épocas de fuerte crecimiento demográfico: la colonización, la guerra y la industrialización. Busan, la segunda ciudad del país, ha vivido estos momentos históricos más fuerte que todas las de su país, por su localización en el final de 
sureste de la península coreana, la más cerca de Japón, y por la posesión del puerto más importante del país.

\section{1 Época de colonización japonesa 1910-1945}

Con la caída de la dinastía Joseon, empieza la colonización japonesa en Corea, a partir de 1910 y durante 35 años hasta el fin de la Segunda Guerra Mundial. Con el propósito de crear una base para la expansión continental de Japón, se planifica una ciudad moderna en Busan. Entre 1909 y 1940, Japón realiza muchas obras en terreno ganado al mar y se instalan depósitos de suministro de agua, puertos, carreteras, ferrocarriles, tranvías y un puente basculante, construyendo además edificios modernos. La implantación de una nueva ciudad colonial suprime el centro de la ciudad original junto con su papel y su función. El centro se mueve a la ciudad mercantil, convirtiéndose en el centro principal de distribución entre la península y el archipiélago de Japón.

Debido al crecimiento industrial y comercial que se dio con Japón, y a las obras civiles a gran escala, la población empieza a aumentar rápidamente; 5 veces entre 1920 y 1945. Por otro lado, en las zonas rurales muchos coreanos perdieron su terreno por el proyecto de censo de tierra y se empobrecieron por la política de aumento de la producción de arroz. Los inquilinos pobres acuden a Busan en busca de un medio de vida. Como la mayoría de los coreanos eran trabajadores temporales, se disponen en lugares de fácil acceso a los talleres y las fábricas, en las afueras de la zona residencial japonesa, área donde se ubican las instalaciones modernas. El plano catastral del año 1933 confirma que el plan del período colonial superpuso una malla sobre la antigua propiedad de la tierra de cultivo, por la parte baja donde tiene el suelo más plano con el terreno ganado al mar. Pero la parte alta, donde empieza la pendiente accidentada, está excluida del plan y allí habitaban los trabajadores coreanos. Fueron ellos los primeros habitantes de aquellos barrios de luna en los años 20 y 30 . De esta manera ya convivían dos realidades muy diferentes en la ciudad, una al lado de la otra.

A lo largo del período colonial, el paisaje urbano de la ciudad original de Busan pierde potencia y oportunidades de reconstruir la tradición con el flujo de la modernización. Por lo tanto, es difícil buscar una combinación de la práctica tradicional y moderna de forma armoniosa, así que se transformó aplicando la forma moderna japonesa a gran escala, dentro del marco colonial. Incluso después de la liberación, con la introducción del estilo occidental sin reflexión sobre el paisaje japonés, se añade la estandarización encima de la pérdida de la tradición. Las contradicciones históricas del doble paisaje urbano de Busan se pueden discutir en este contexto.

Tranvía eléctrico, 1910-30 En el fondo de la foto, se ve el puente basculante levantado.
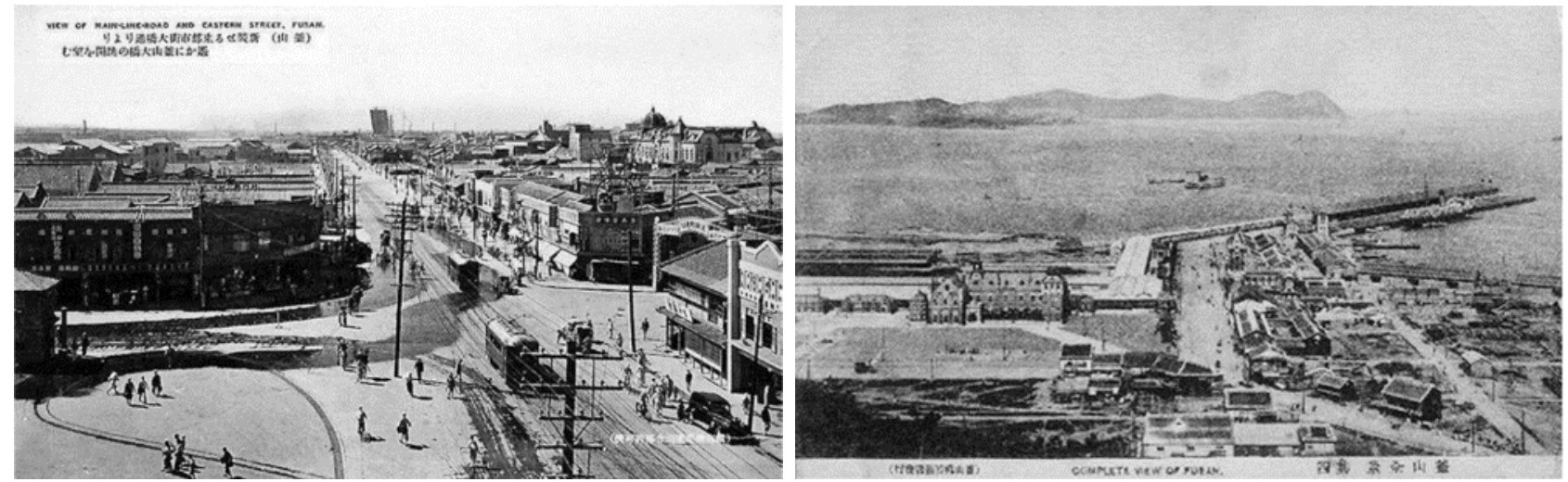

Puerto de Busan, 1930 La estación y la aduana, al lado izquierdo y al lado derecho respectivamente. (http://abcd.busan.go.kr, 2014) 

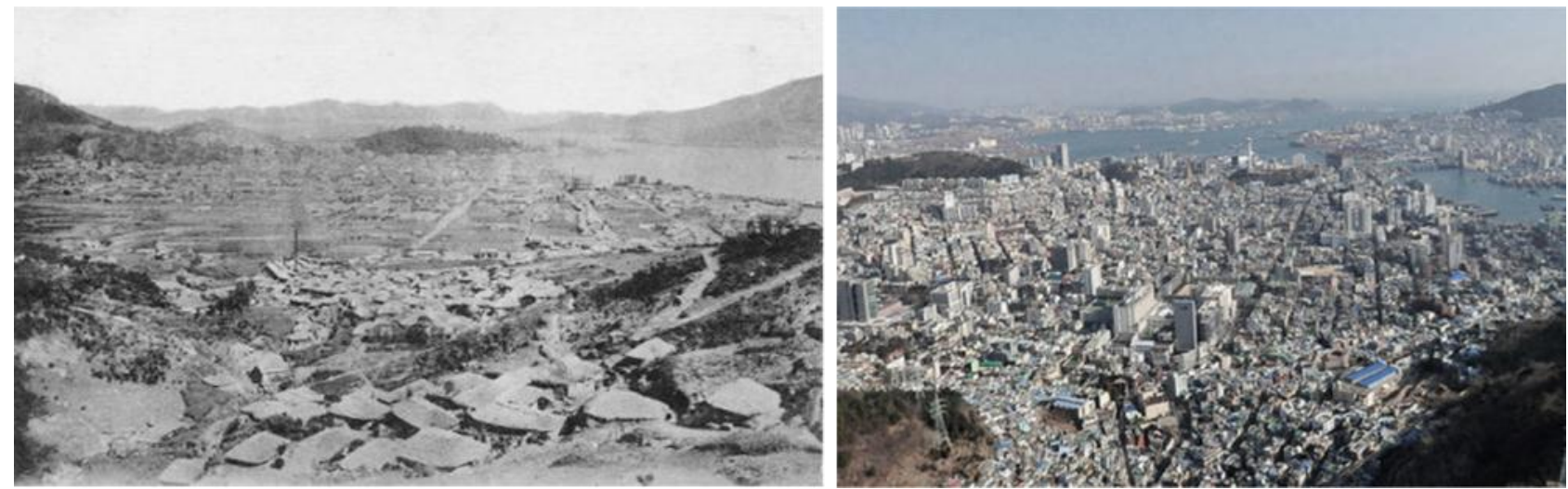

Barrio de los coreanos, $1910 \mathrm{En}$ el fondo, se observa la retícula de la ciudad moderna proyectada para los japoneses.

(http://blog.daum.net/pcbc-tv/308, 2014)

Foto actual del mismo lugar a la derecha

(http://abcd.busan.go.kr, 2014)

\section{2 Época de la independencia y la Guerra de Corea (1945-1953)}

Cuando Corea recuperó su independencia con el fin de la Segunda Guerra Mundial, los japoneses se marcharon de la península, pero la población de Busan aumentó mucho más por el regreso de compatriotas a su país por el puerto de Busan. Es difícil determinar el número exacto de coreanos que regresaron después de la liberación, pero se estima que más de 200 mil personas llegaron a Busan, cifra que representaba una cuarta parte de la población de ese momento.

Cinco años después de la independencia, en el año 1945, estalló la guerra de Corea y más de 700 mil coreanos se refugiaron al sur llegando a Busan y se formó un espacio de supervivencia sin preparación previa. De 1945 a 1951, la población de la ciudad se triplicó. Se instalaron más de 40 campos de refugiados en la empresa cerámica en Bongrae-dong de Yeongdo, en Daeyeon-gogae, en Nambumin-dong, incluyendo más de 40 campamentos con capacidad solo para 70 mil personas. Alrededor de 400 mil personas que no pudieron entrar en los campos de refugiados, sin ningún familiar o recursos económicos, se asentaron en la colina adyacente al centro de la ciudad y en las instalaciones portuarias como única manera de salvar sus vidas. Se estima que había más de 15 mil barracas alrededor de las pendientes de la montaña Yongdu y Jung-gu cerca del centro de la ciudad y más de 40 mil en toda la ciudad.
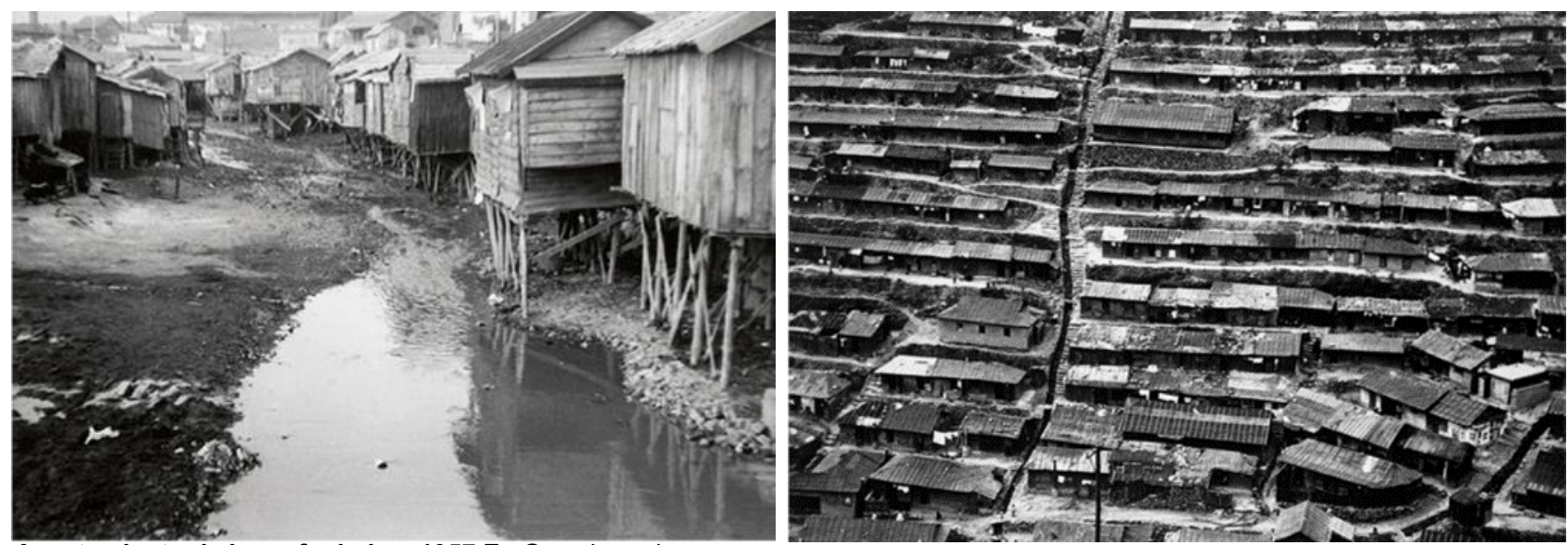

Asentamiento de los refugiados, 1957 En Gamcheondong

(http://blog.daum.net/pcbc-tv/308, 2014)

\section{3 Época de la industrialización y la mejora de viviendas (1953-1990)}

La explosión demográfica continuó gracias a la industrialización a partir de los años 60 y con esto, los barrios de las montañas se extendieron aún más. El Plan Quinquenal de Desarrollo Económico, desarrollado bajo gobierno militar entre 1962 y 1986, creó una gran demanda de mano de obra, lo que causó olas de migración desde las zonas rurales a las ciudades. Como puerto principal del país para la exportación, Busan fue una de 
las ciudades más importantes de la industrialización. En Busan se construyeron muchas instalaciones industriales aprovechando y modificando las infraestructuras de la época colonial. Desde la industria ligera, como fábricas de calzados, tejidos, redes de pesca y procesamiento, se pasó a la industria pesada, como fábricas de maquinaria y construcción naval.

Como consecuencia de la industrialización acelerada y los proyectos urbanos, la situación de la vida de los barrios de Luna cambió drásticamente. Hubo una serie de políticas y promesas sobre los barrios de Luna. Como resultado de varios proyectos de mejoras, se cambió la imagen de las chabolas precarias y se mejoraron las condiciones de las viviendas significativamente. Muchos callejones antiguos y zanjas se convirtieron en calles pavimentadas. También tuvo éxito la extensión de carreteras, la construcción de vías de comunicación y la accesibilidad. Sin embargo, no había una visión a largo plazo para la mejora de los barrios de barracas, ya que había problemas más urgentes, como la pobreza total y la extrema escasez de vivienda tras la guerra.

Puerto de Busan, 1966 Ampliación de la instalación industrial
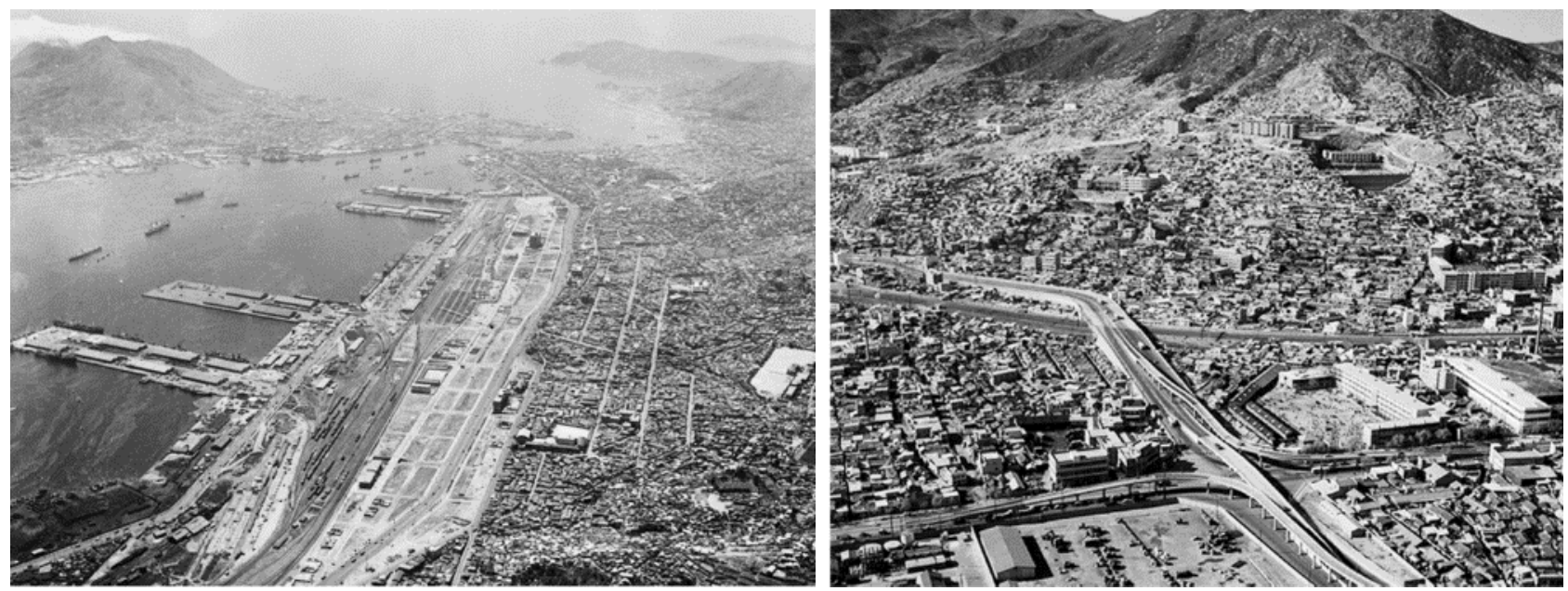

Carreteras elevadas, 1960 En el fondo, se puede observar la ocupación de la montaña por los asentamientos informales.

(http://blog.daum.net/pcbc-tv/308, 2014)
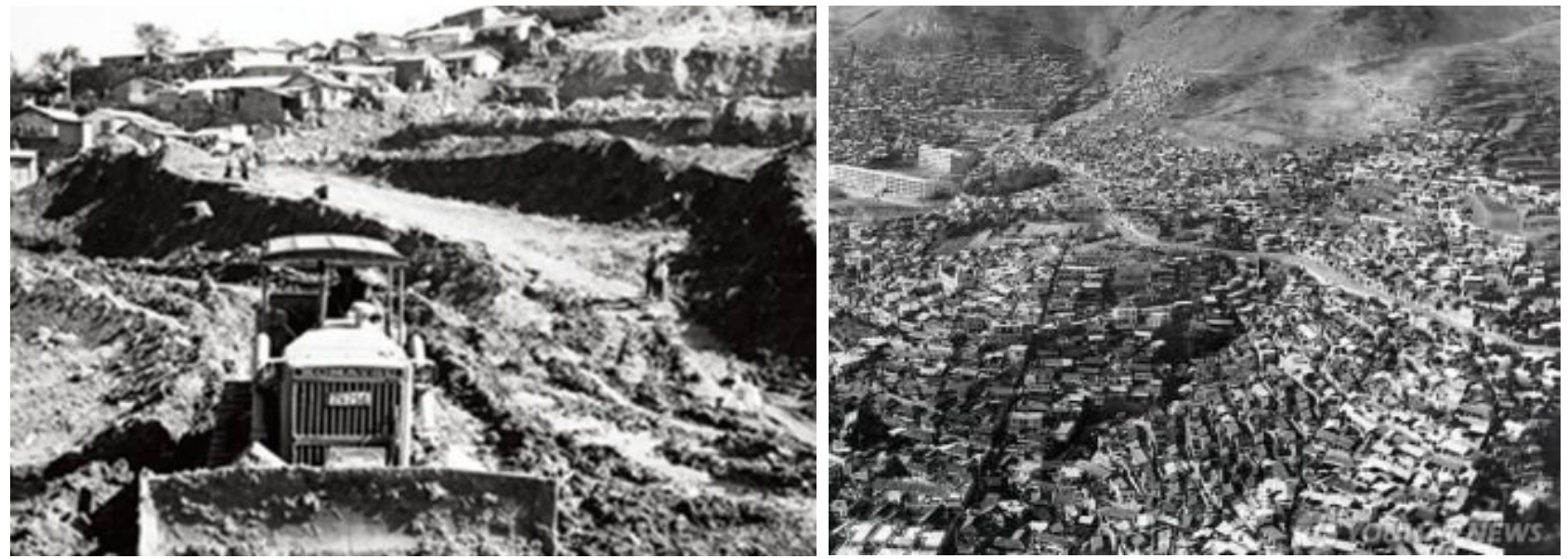

Demolición de barracas, 1960

(산복도로 르네상스, 부산발전연구원 부산학 연구센터, 2010)

Carretera de ladera, 1970 En Sujeongdong

(http://blog.daum.net/pcbc-tv/308, 2014)

\section{4 Época de pérdida de la población (1990-2015)}

Tras varias décadas con una alta tasa de crecimiento, su proceso de industrialización empezó a desacelerar entrando en la etapa de desindustrialización. En el año 1990, Busan ya empieza a perder población. La pérdida de habitantes en los barrios de Luna fue más fuerte que la disminución de la población en el resto de la ciudad. En el año 2009, el Municipio publicó un proyecto de regeneración de estos barrios, designando 54 barrios como áreas de rehabilitación. Sin embargo, la "regeneración urbana" suele orientarse a una consigna 
de otra "remodelación" sin considerar el soporte espacial, sin tener una comprensión de los tejidos existentes y ni una innovación en los criterios de intervención. De esta manera, los barrios de luna todavía siguen teniendo un crecimiento "no dibujado".
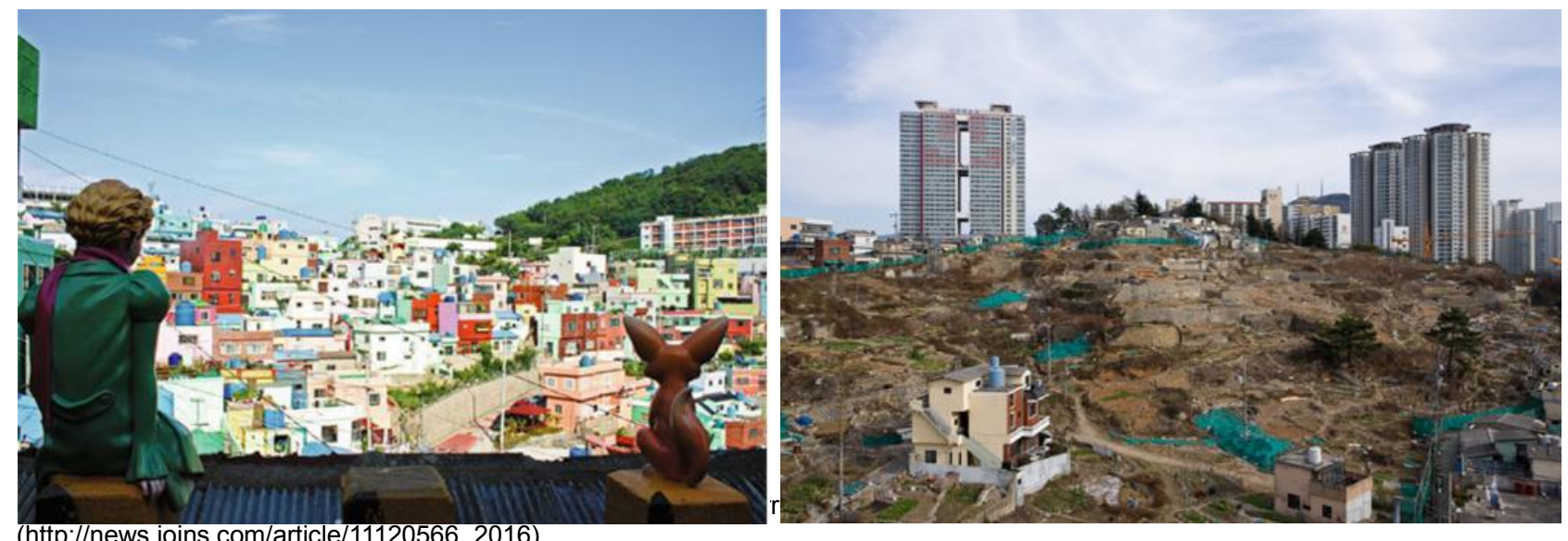

Demolición de barrios

(http://abcd.busan.go.kr, 2014)

\section{MORFOLOGÍA DE LA CIUDAD INFORMAL DE BUSAN}

Este estudio se ocupa de los elementos físicos, explicando cómo se manifiesta la historia del crecimiento de la ciudad en su espacio urbano para saber las características que condicionan su transformación futura y para materializar cuestiones decisivas. Es buscar su orden y lógica propia de la ciudad informal que solamente son invisibles hasta que no se descubren. Sin embargo, no existe documentación gráfica de los sucesivos procesos, por lo que el único método de análisis formal es observar la ciudad actual considerándola como el resultado de una continua transformación. Desde la observación, se perciben y distinguen diferentes condiciones, por lo que el trabajo consiste en reconocer las diferentes variables y dibujar la relación entre las mismas.

\subsection{Estructura espacial del crecimiento de Busan}

Las condiciones geográficas resultan especialmente determinantes en la estructura de varias escalas, ya que Busan tiene una topografía muy característica. Como primera aproximación estructural, se observa su configuración topográfica como expresión de la organización espacial. En otras palabras, se observa la relación entre la condición geográfica y la localización de diversos tejidos urbanos. Primero se diferencian los distintos tejidos según su uso dominante (comercial, industrial, educacional y residencial) y también según su forma (residencial, barrio de luna, barrio de desahuciados, apartamentos municipales, apartamentos habitacionales y apartamentos en torres). Luego se analizan los patrones de ubicación de cada tejido en el área urbana entre el mar y la montaña, desde la cota 0 a los 140 metros sobre el nivel del mar. 


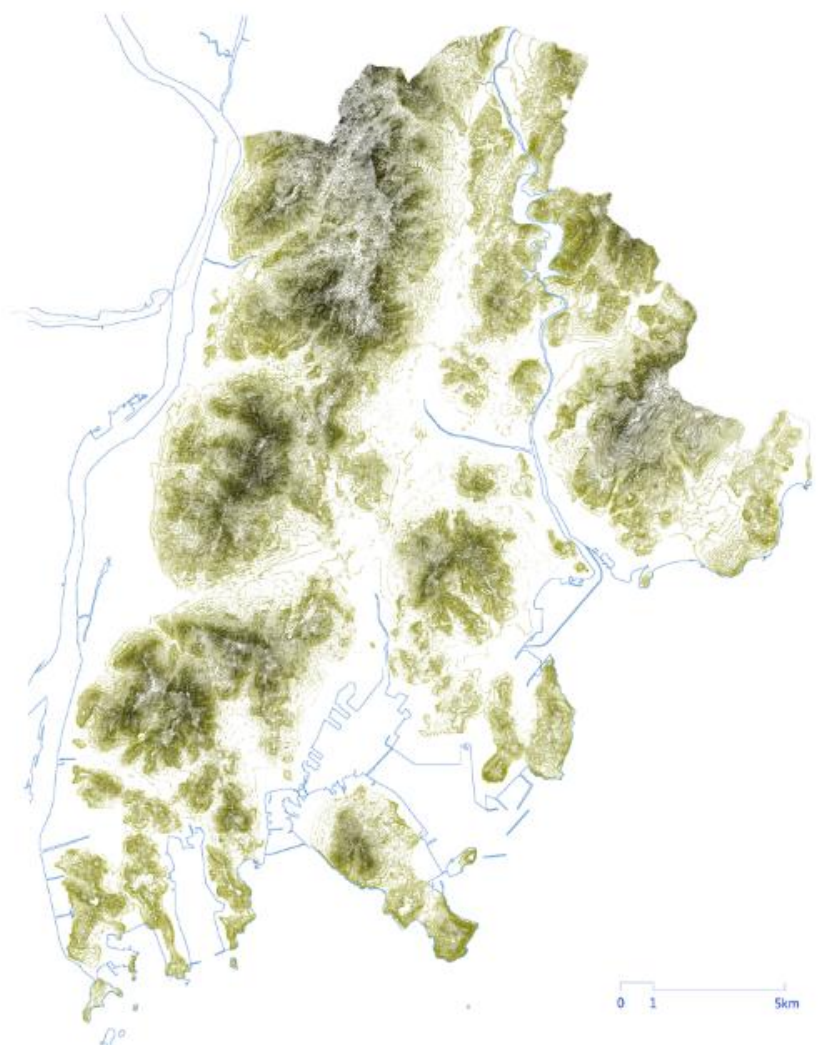

Relieve del terreno Al lado izquierdo transcurre el río Nakdong, al lado derecho el río Suyeong que se une con el riachuelo Oncheon y, en el medio, el río Dongcheon. $46 \%$ del área urbana es montañosa con una altura máxima de $800 \mathrm{~m}$. Elaboración propia

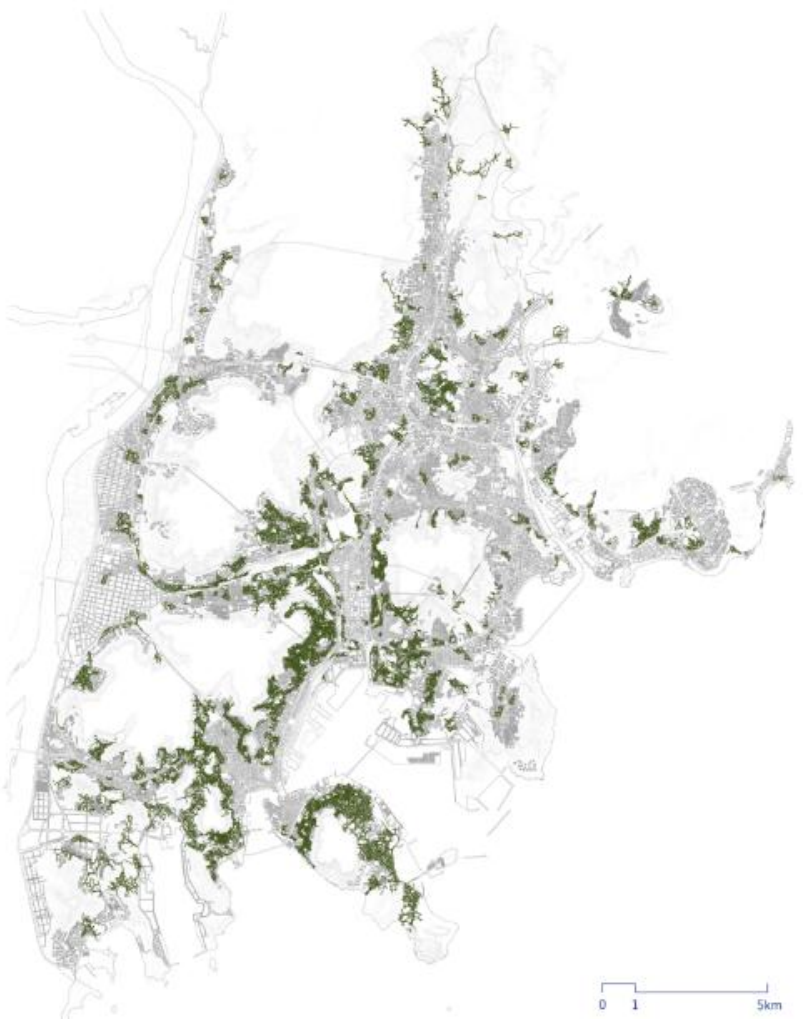

Barrio de Luna Se sitúa en las laderas accidentadas de las montañas por encima de la altura de $20 \mathrm{~m}$. Elaboración propia

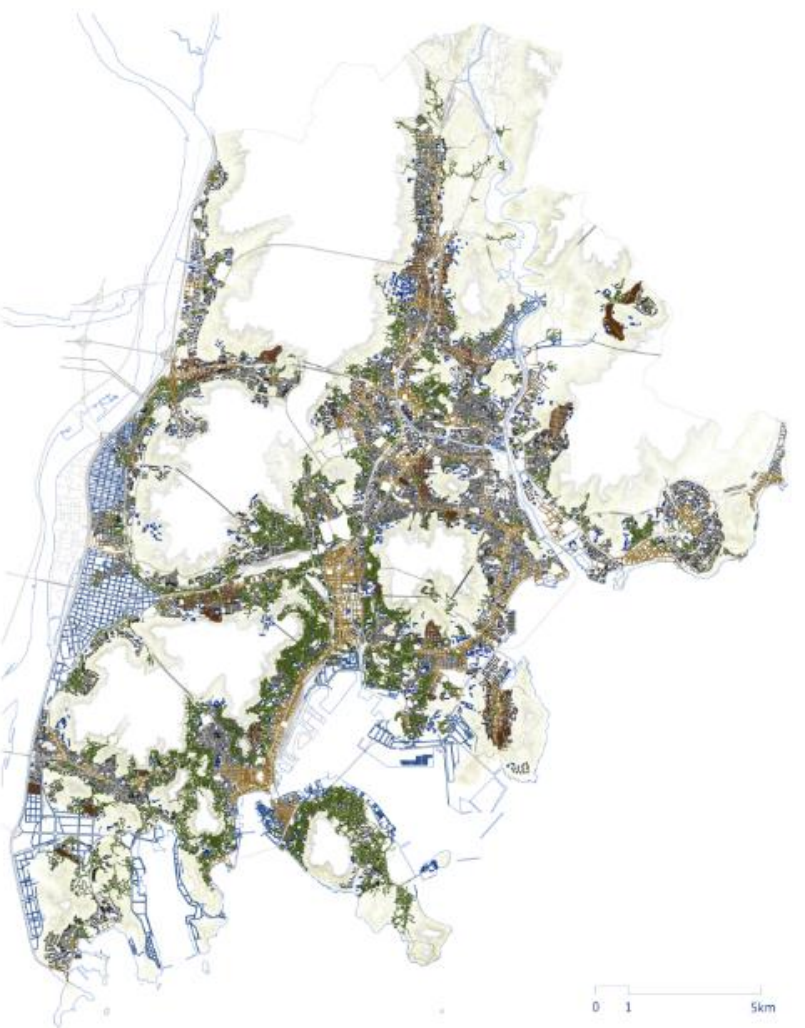

Cota de nivel 0-200 $\mathrm{m}$ El espacio urbano construido ocupa de la altura de 0-150 metros sobre el nivel del mar. Elaboración propia

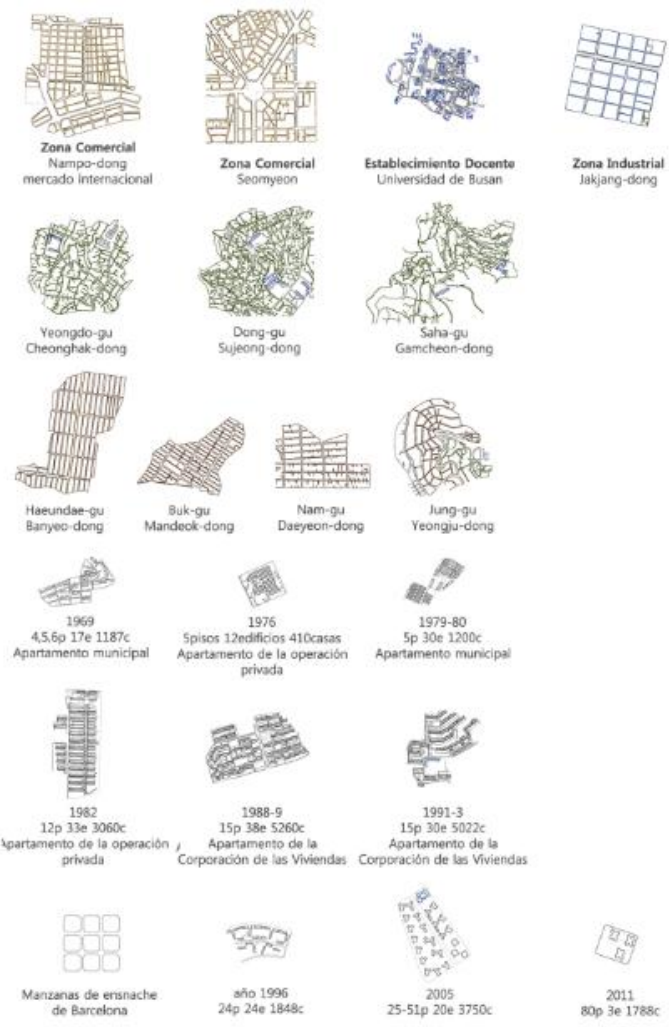

Tejidos urbanos

Elaboración propia 

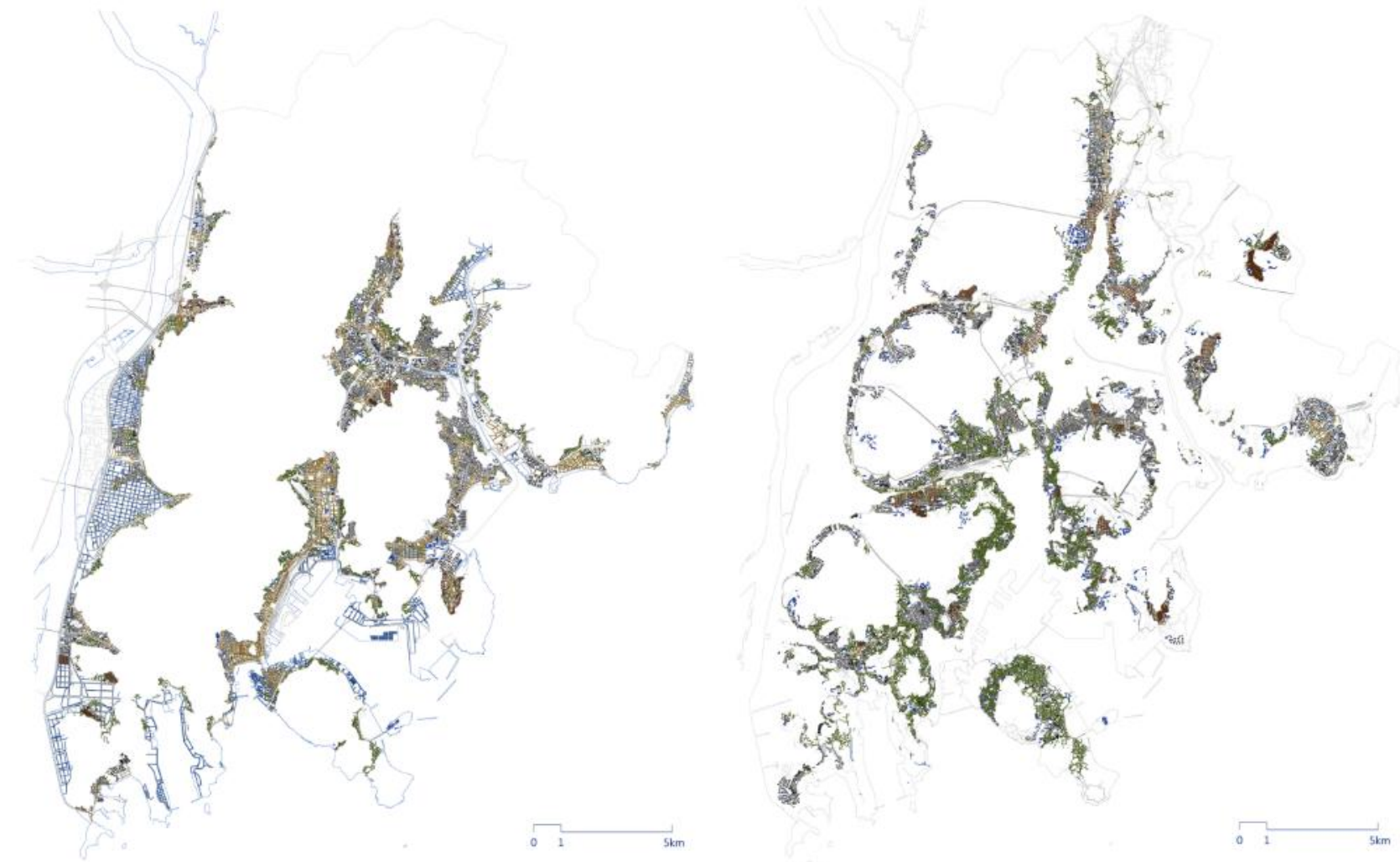

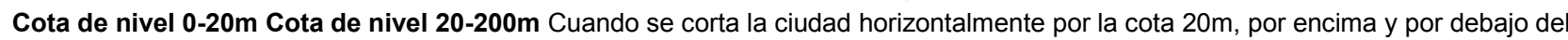
nivel aparecen los tejidos distintos, con diferentes colores en los dibujos.

Elaboración propia

La zona comercial, el centro de la ciudad actual, corresponde a la urbanización colonial de los años 19101945 desarrollada en trama regular. La zona industrial está concentrada en la costa del terreno ganado al mar en la época colonial, posteriormente ampliado en la época industrial y en la rivera desarrollada de la nueva zona industrial de la suburbanización. Los colegios y universidades aparecen en grupos de edificios y campos de recreo. Los tejidos residenciales se diferencian bien formalmente según la época de su construcción. Los barrios de luna se sitúan en las laderas de las montañas en tramas irregulares. En localizaciones similares, cerca de los barrios de luna, emergen paquetes de tejidos regulares en mallas estrechas. Son los barrios de los terrenos y/o viviendas municipales desarrollados para los desalojados de la demolición de las barracas en los años 60 y 70 . Dentro de los barrios de luna y de los barrios de desahuciados aparecen viviendas públicas de los años 60 y 70 dispersas en apartamentos de menos de 5 pisos. Particularmente los primeros apartamentos municipales a menudo se emplazan al borde de los barrios de luna con las montañas. Se supone que los construyeron junto con la demolición de barracas que se situaban encima de los 130 metros sobre el nivel del mar. Los grupos de apartamentos de 10 a 20 pisos corresponden al desarrollo a modo de compra de toda la superficie del boom de la construcción de los años 80 y 90 . Por último, los paquetes de apartamentos en torres con buen acceso a las infraestructuras principales y buenas vistas al mar son construcciones del cambio de siglo.

Las ubicaciones de cada tipo de tejido aparecen concentradas siguiendo un cierto patrón. Cuando se corta la ciudad horizontalmente por la cota $20 \mathrm{~m}$, por encima y por debajo del nivel aparecen los distintos tejidos, de diferentes colores en los dibujos. Es decir, los distintos tejidos aparecen según el nivel, como una estratificación geológica, en orden de: mar, zona industrial, zona comercial, barrios de luna y barrios de los desahuciados $(20 \mathrm{~m}-140 \mathrm{~m})$, los primeros apartamentos municipales y montaña. Sin embargo, los apartamentos de los años 1980 a 2000, aparecen a cualquier altura y por todas partes.

Esta distribución espacial se repite en cada montaña de la ciudad y aparece en forma de anillos. De esta forma, tiene una continuidad de patrón en horizontal, en el mismo nivel, pero en vertical, entre tejidos distintos, no hay mucha conectividad. Para acceder a la montaña se debe pasar por los barrios de luna que no tienen carreteras básicas, y para acceder al mar queda bloqueado el paso por zonas industriales que rodean la costa. Es decir, la ciudad tiene una estructura que excluye el mar y las montañas de su área urbana. Además, no es difícil imaginar que esta separación espacial refleja una organización que gira alrededor del valor de suelo y 
de la clase social también. Debido a la concentración de la infraestructura y los servicios urbanos sólo en la altura baja, existe un grave desequilibrio estructural y funcional. Considerando que la ciudad está formada por 8 montañas, o 8 anillos, repetidos, se podría centrar el estudio en un único anillo, y utilizarlo como un ejemplo aplicable a otros anillos.

De este modo, entendiendo que la forma conoidal de la montaña es la sumatoria de los anillos horizontales desde nivel del mar hasta su cúspide, se podría acotar el ámbito de análisis a un eje vertical el cual, por lo antes explicado, contendría un segmento de cada capa horizontal; luego, el análisis de este eje podría ser replicable al resto de laderas de montañas que conforman la ciudad.

En el estudio se intenta explicar la morfología de la ciudad variando en estas escalas, que "la misma realidad puede aparecer desordenada a una escala y ordenada en otra diferente" (Capel, 2002:99).

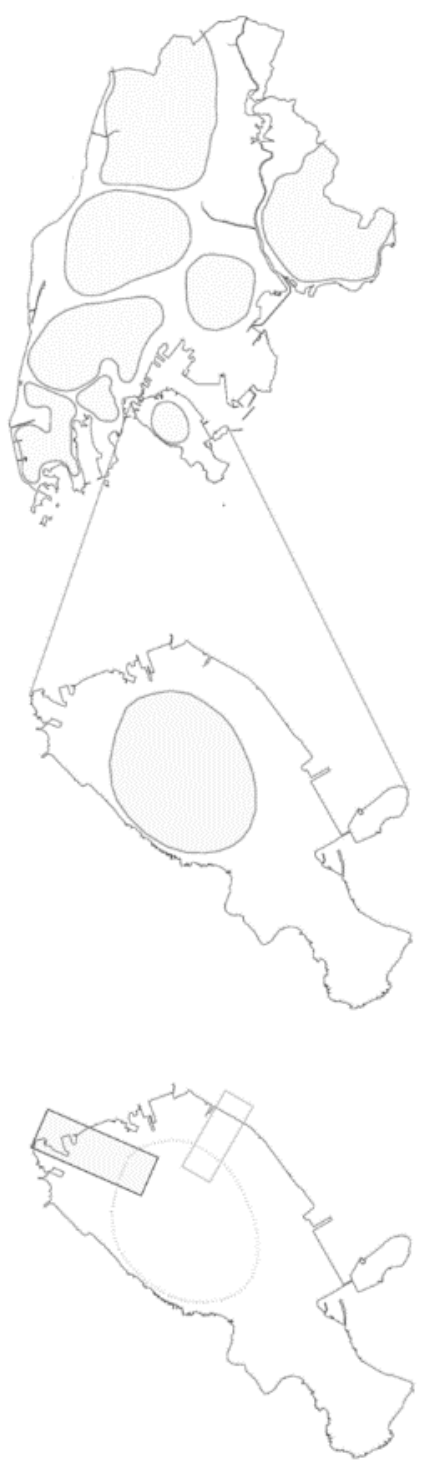

\subsection{Ordenación topográfica}

Ocho anillos

Un anillo

Un eje

Elaboración propia

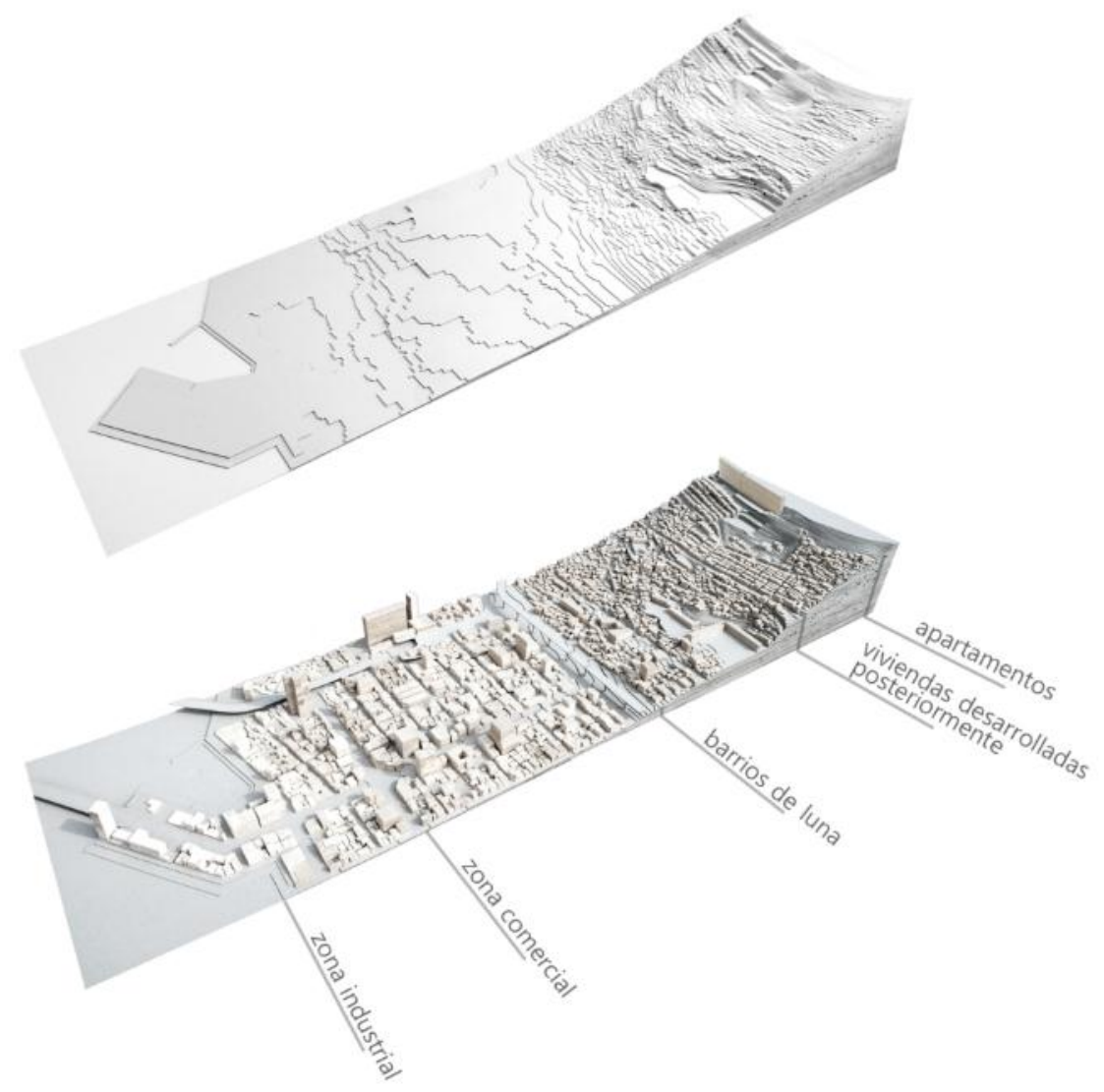

Sección de un eje

Los distintos tejidos aparecen según el nivel, como una estratificación geológica

Elaboración propia 
A continuación, se explica la morfología del asentamiento informal centrándose en un anillo, la isla Yeongdo, que se dice que es una miniatura de Busan por lo que ha vivido en cada acontecimiento histórico de Busan. Lo que perdura más a lo largo del tiempo entre los elementos construidos de una ciudad es el trazado de las calles. Las parcelas pueden haberse aunado y dividido, los edificios pueden haberse destruido y reconstruido, pero las calles, el espacio común del barrio, suele permanecer.

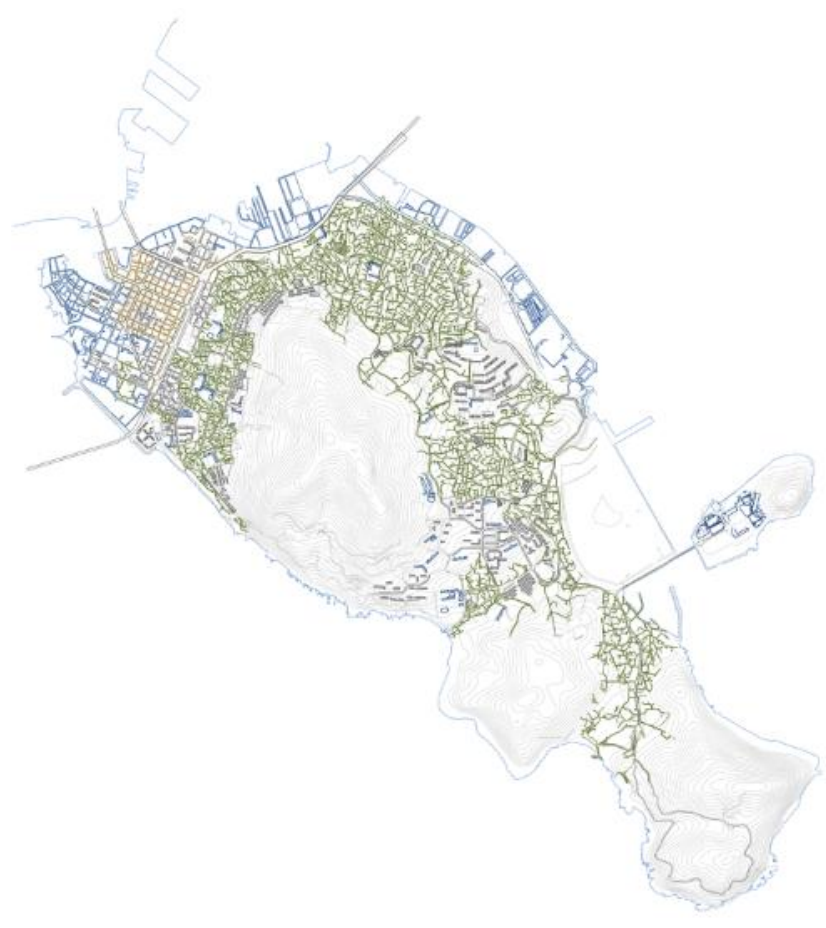

Un anillo, Yeongdo

Elaboración propia

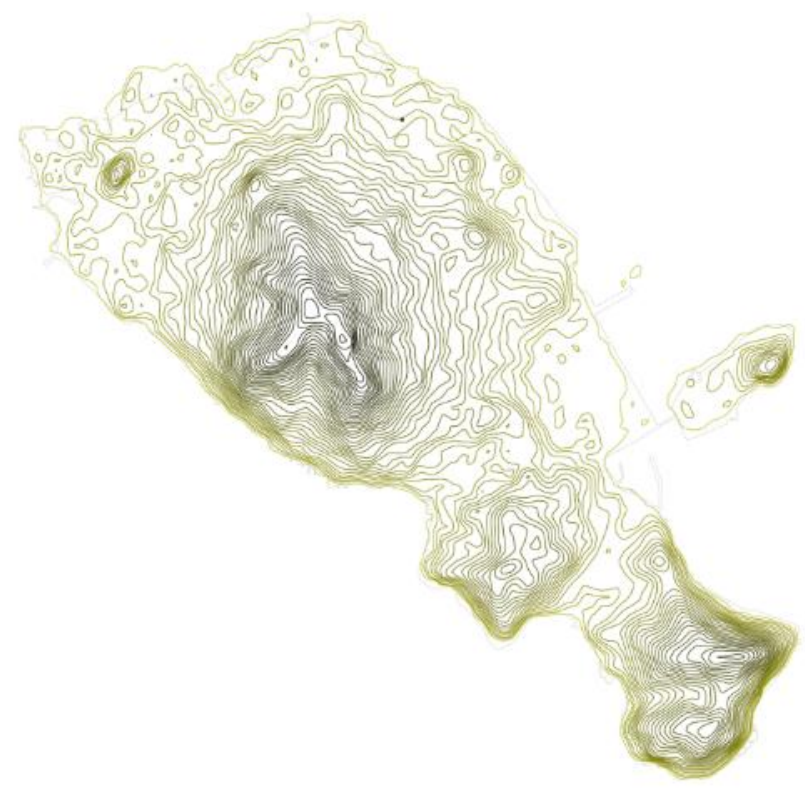

Relieve del terreno

La altura máxima de la montaña Bongrae es de 396,2 metros sobre el nivel del mar.

Elaboración propia

Por la misma razón, entendiendo que la forma irregular viene fundamentalmente condicionada por la configuración topográfica, en el siguiente estudio se busca el orden geográfico en el sistema viario. Un terreno inclinado tiene una direccionalidad porque con la pendiente se puede leer el sentido de arriba y abajo. Con lo cual, se clasifican las calles por dos órdenes que explican esta direccionalidad: verticales y horizontales. La dirección perpendicular a las curvas de nivel (el sentido ascendente y descendente) es vertical. Luego, la dirección paralela a las curvas de nivel (el sentido continuo de la cota) es horizontal.

Las vías verticales y horizontales dibujadas separadamente muestran las características bien destacadas de la morfología de la ciudad formal e informal en contraste. Diferencian fuertemente dos realidades: la ciudad baja, con una trama regular, y la ciudad alta, con una trama totalmente irregular. Las vías verticales geográficas de la parte alta son las que se conectan a la parte baja inmediatamente, ofreciendo mucha permeabilidad. Es mejor decir que las vías verticales de la ciudad baja continúan a la ciudad alta, pero al llegar a la pendiente elevada pierden su rectitud y uniformidad de anchura obedeciendo al orden geográfico. La mayoría de las vías verticales tienen tramos de escalera y tienen una pendiente que hace difícil la construcción de carreteras en su dirección. En cambio, en las vías horizontales hay carreteras insertadas en los años 60 por la reforma de los barrios de barracas ejecutada por el municipio. Fue el primer intento de urbanización institucional y de conexión entre los barrios de luna, que crecieron a partir de una construcción por iniciativa individual y fragmentada. 


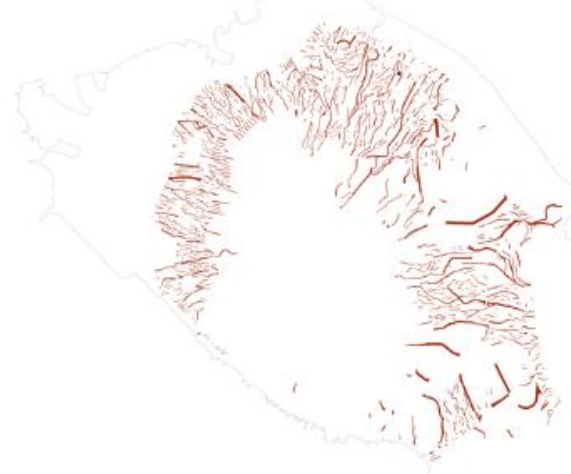

Vías verticales geográficas

Elaboración propia

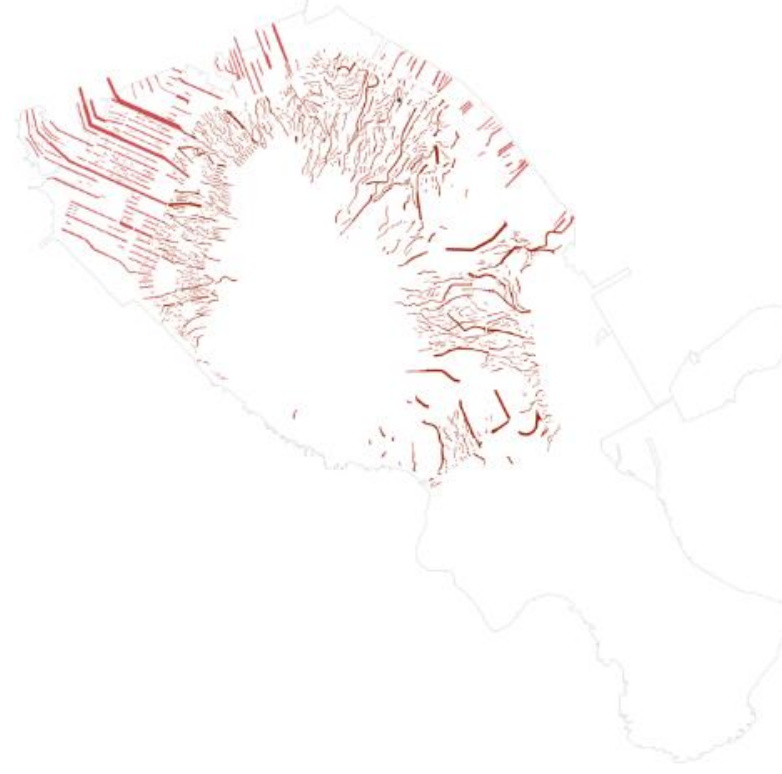

Vías verticales geográficas + geométricas Elaboración propia

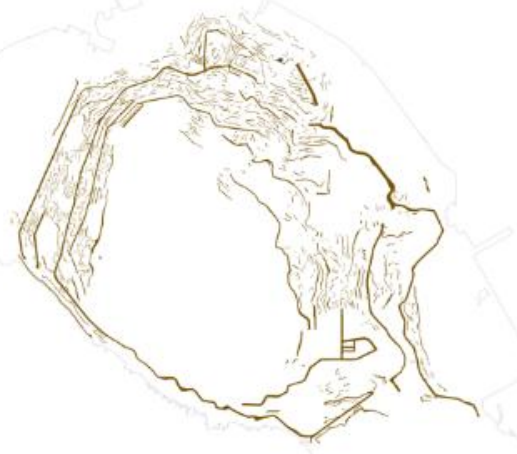

Vías horizontales geográficas

Elaboración propia

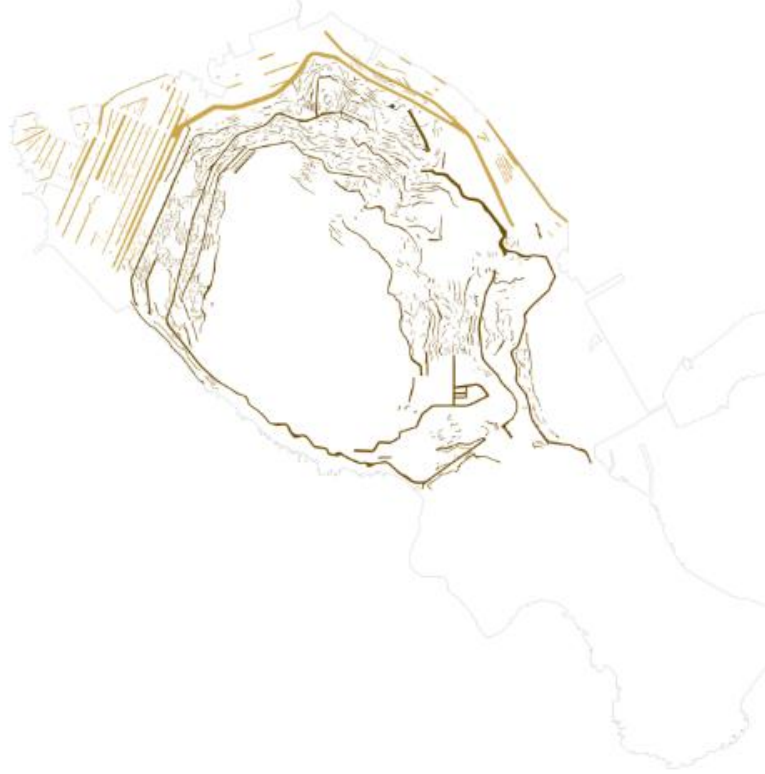

Vías horizontales geográficas + geométricas

Elaboración propia

La trama viaria irregular no significa necesariamente que esté desordenada. A continuación, de verticalidad y horizontalidad viarias, se observa la conectividad entre ellas. En el desarrollo de los barrios de luna no había un establecimiento de la jerarquía funcional de las calles. Se desarrollaron las calles como un simple acceso a cada parcela. Sin embargo, sin consideración de la irregularidad de anchuras, del grado de pendiente o del tipo de calle, se podría designar un orden según la distribución interna del barrio. Es decir, una vía que tiene mayor conectividad a otros viales tiene más importancia por su mayor distribución.

Primero, se clasifican las vías que se cierran entre ellas creando una unidad delimitada por estas calles que se llamaría "manzana" en una ciudad convencional. Luego, se distinguen las calles distribuidas dentro de esta unidad, que conectan a las que definen la unidad. Por último, se disciernen las calles que dan acceso solo a 
un grupo de viviendas (callejones sin salida). Este orden de la distribución también responde a la definición de los espacios comunes según el carácter de más público a más privado. Por tanto, la trama viaria de los barrios de luna es un sistema bastante organizativo.

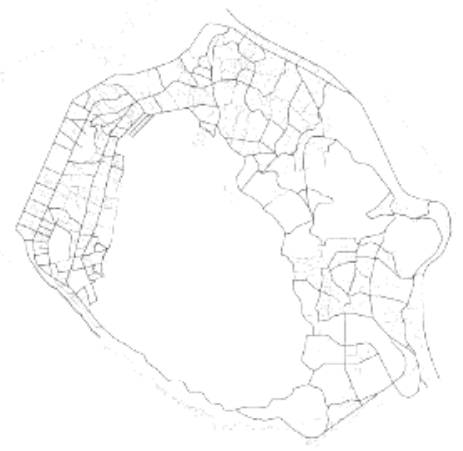

Vías verticales y horizontales geográficas Elaboración propia

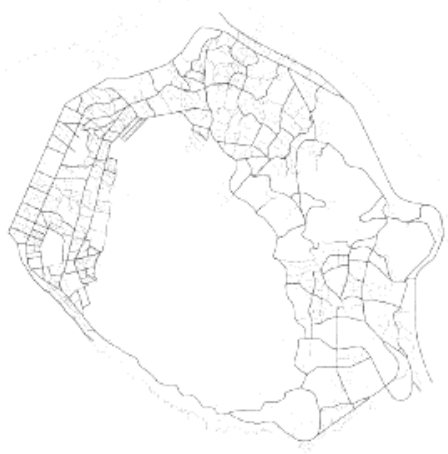

$1^{\text {a }}$ malla

Elaboración propia

Sin embargo, estos callejones son el primer espacio compartido y colectivo, desde vida residencial a vida social. Son el lugar de acceso a cada vivienda individual, el de vida comunal de los habitantes, el de ocio, el de la comunicación entre los residentes, el de la extensión de la escasez espacial del interior y a veces el de los medios de vida asociados al trabajo. En la cultura urbana de Corea, donde está ausente la idea de "plaza", los callejones constituyen el soporte espacial característico del "intercambio social". En este sentido, "la cultura de callejón" se identifica como cultura comunitaria, donde el callejón proporciona la base material del espacio público (Instituto de Estudios del Desarrollo de Busan, 2010). Además estos callejones han sido el elemento fundamental de la transformación de los barrios. Ellos se convirtieron en el soporte de la instalación de servicios básicos para la vivienda: suministro de agua, electricidad, desagües, etc.

\section{MEJORA DE LA CIUDAD INFORMAL Y CONDICIONES ACTUALES}

Por último, se enfoca en el proceso de la transformación de los barrios de luna demostrando su problema, cómo las operaciones recientes han empeorado las condiciones residenciales por ignorar la lógica propia de la ciudad informal. Con ello, evidencia la importancia del estudio de la morfología de la ciudad informal y que su futura transformación se debe basar de la ciudad informal, no de la otra.

Joan Busquets (1982) resume los tres tipos de procesos que pueden provocar los planes y la actuación de la administración en barrios de urbanización marginal. Uno de ellos es la "Congelación" del barrio, estimando que ha seguido un proceso defectuoso. Es una actuación que supone un impacto muy fuerte sobre el barrio, y rompe las expectativas de mejora y consolidación de las iniciativas de los residentes en los barrios. El segundo es la "Remodelación" del barrio, que trata de erradicar la edificación "marginal", sustituyéndola por casas "normales". Por último se refiere a la "Mejora progresiva", que considera de forma prioritaria las posibilidades de urbanización del barrio y estudia las condiciones de legalización del mismo, en orden a superar la "marginalidad" existente hasta ese momento, tanto desde el punto de vista urbanístico como legal. En Barcelona, desde finales de los años 60 , hubo intensos debates sobre las formas de intervención y un intento de construcción teórica. La dificultad de aplicar los modelos de propuesta típicos obliga a innovarlos 
como única forma de potenciar un desarrollo del barrio en la línea de una mejora progresiva. Por tanto, se considera que un estudio preciso y detallado del barrio es fundamental para entender la situación actual, sus variables más características, y para definir una valoración sintética del mismo en relación a las pautas de intervención.

Sin embargo, en el caso de Busan, ha habido varios intentos de transformación de los barrios de barraca pero sin consideración a la especificidad del asentamiento. En los años 60, hubo mucha "Remodelación" con demolición y desalojos forzados que dieron lugar a una mayor proliferación de barrios de barracas en otras zonas. También hubo un intento de "inserción" de carreteras con los servicios básicos. Pero estas intervenciones se ejecutaron separadamente, con intervalos de años y de maneras diversas, por la falta de inversión pública. Luego, en los años 80 y 90, los barrios quedaron "congelados" desde el punto de vista de la planificación pública, a la espera de otra "remodelación" con reconstrucción de los apartamentos o más instalación de carreteras. Con la máxima prioridad en la producción industrial, una vez instalados los servicios básicos, el medio ambiente residencial se consideró menos importante. Mientras tanto, los barrios subsistieron a lo largo del tiempo y se consolidaron poco a poco muchas veces por el esfuerzo de los propios residentes. De esta manera, tras intervenciones esporádicas, los barrios de luna siguieron incompletos sin que ninguna acción se completara totalmente.

Incluso las operaciones recientes han empeorado las condiciones residenciales. La continua inserción de carreteras es una superposición del modelo convencional. Se trazaron nuevas carreteras directamente encima de las calles existentes como una mera extensión y ampliación. De esta manera, las calles escalonadas se convirtieron en carreteras construidas con muros de contención para salvar el desnivel existente. Esta modificación del terreno destruye la vinculación entre las viviendas y los accesos desde la calle. Las viviendas, que eran unas terrazas encima de los bancales, ahora quedan por debajo del nivel de la calle, con un acceso por unas escaleras para salvar este nuevo desnivel. La modificación del terreno sin considerar emplazamientos existentes deteriora accesos o corta la conectividad entre los vecindarios. Por otro lado, debido al aumento del transporte privado, las viviendas vacías se sustituyeron rápidamente por áreas de aparcamientos en lugar de convertirlas en espacio público. La introducción de lógicas formales para asemejar estos barrios a formas de crecimiento convencional, niega el propio proceso de crecimiento de los mismos.
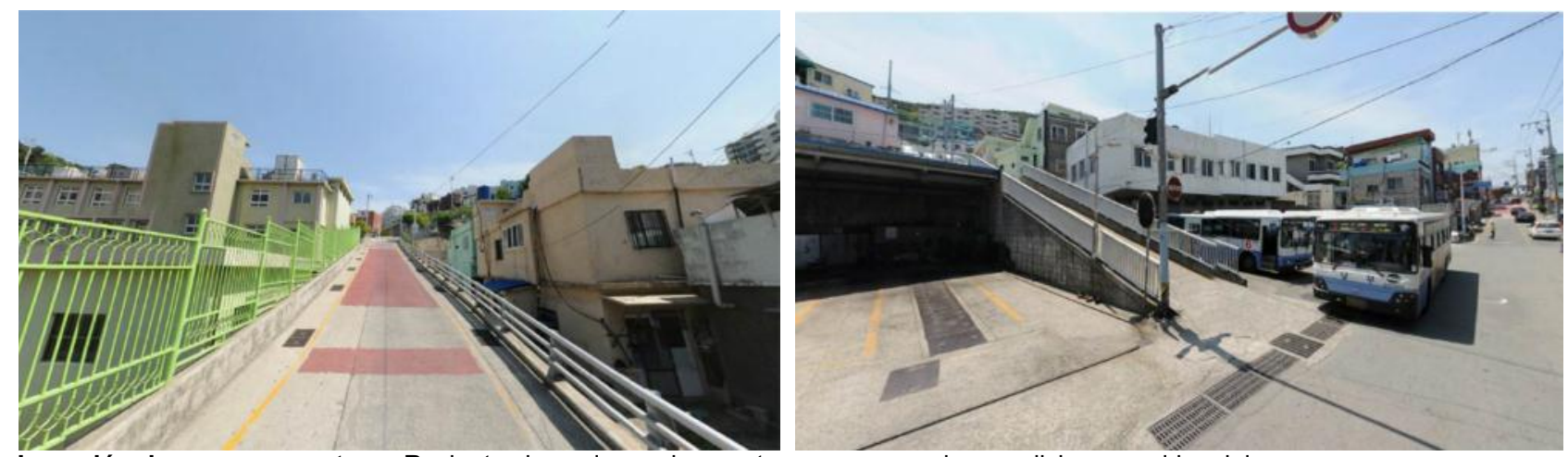

Inserción de nuevas carreteras Recientes inserciones de carreteras empeoran las condiciones residenciales.

(map.naver.com, 2016)

Supuestamente, la continua introducción de lógicas formales no hace que la ciudad informal se convierta en formal. En conclusión, si se siguen orientando las intervenciones a asimilar la ciudad informal a una ciudad formal, habría que erradicar físicamente los barrios de luna para sustituirlos por barrios formales.

En la primera década del nuevo siglo, se lleva a cabo una "regeneración" de los barrios. Pero cabe preguntarse qué se está perdiendo y cuál es el objeto de esta regeneración. En el fondo, hablar de "regeneración" es presuponer que ya se acabó su proceso o su posibilidad de "desarrollo" o "evolución". Se considera que los barrios de luna pueden ser un recurso histórico y cultural, por tanto "turístico". No se considera una innovación de su uso "residencial".

El proyecto de "Renacimiento de las carreteras ladera de la montaña", consiste en mejorar el acceso a los barrios y el ambiente residencial, instalar espacio público, establecer su identidad e incentivar la competitividad de los barrios. Sin embargo, su propuesta es confusa respecto a quiénes son los destinatarios de la intervención: los residentes o los turistas. Se ampliaron las zonas de aparcamientos en los barrios para mejorar el acceso, se estimuló la construcción de nuevas viviendas para mejorar el ambiente residencial, se 
instalaron miradores de espacio público, se designaron unas "calles culturales" para establecer la identidad del barrio y se promovieron comercios en los barrios para incentivar la competitividad. Así, se habla del éxito del proyecto de "regeneración" a partir del número de turistas que han visitado los barrios. De hecho, el barrio Gamcheon, que ha sido el primer barrio del proyecto, recibe un millón de turistas al año. La vida de los habitantes de los barrios suele convertirse en "espectáculos" de producto turístico y se producen conflictos entre residentes y visitantes.
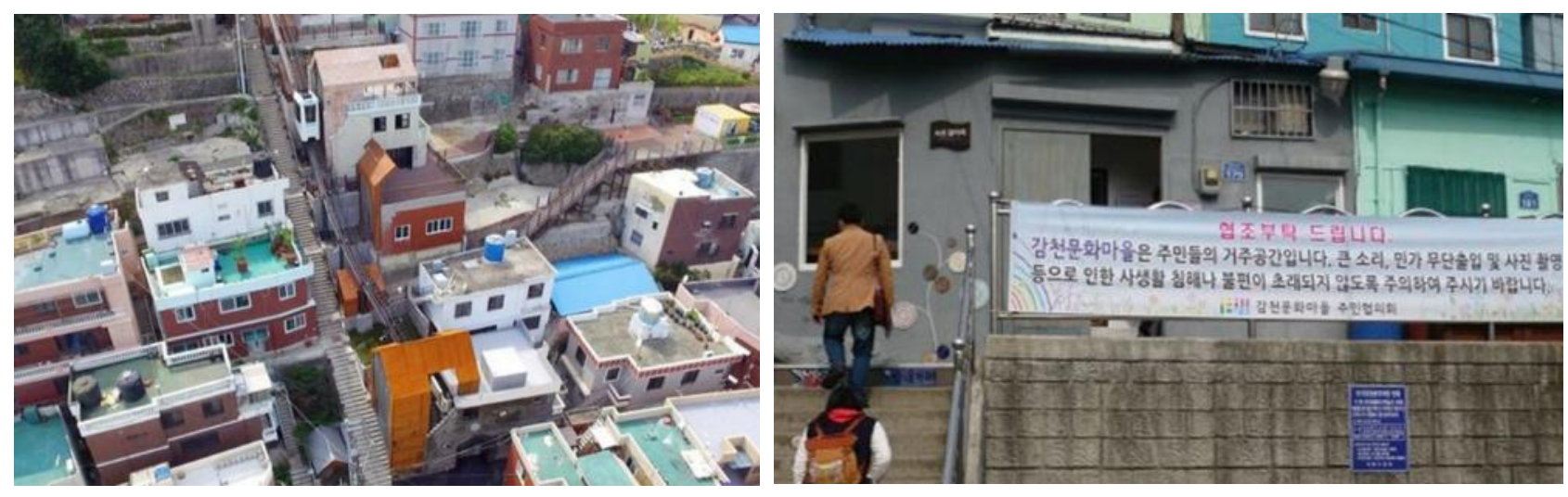

\begin{abstract}
Intervención del proyecto
"Renacimiento de las carreteras ladera de la montaña" Instalación de mono carril

(http://blog.naver.com/PostView.nhn?blogld=redis12\&logNo= 220759391053\&parentCategory $\mathrm{No}=$ \&categoryNo=48\&viewD ate=\&isShowPopularPosts=true\&from=search, 2016)
\end{abstract}

\begin{abstract}
Turistas en los barrios
"Barrio cultural, Gamcheon, es un espacio de los residentes. Por favor, tengan cuidado de no dar lugar a una invasión de la privacidad por entrar casas privadas, tomar fotos o hacer ruidos. -Asociación de vecinos"

(http://news.joins.com/article/11120566, 2016)
\end{abstract}

Esta "regeneración" es una consigna de otra "remodelación", de residencial a un "parque temático" o de otra "congelación" en la conservación de la historia. En el fondo es tratar los barrios de luna como un tipo de residencia de una época pasada que nunca puede convertirse en una residencia satisfactoria. Pero si pierde su función original de "residencial" sin potenciar a los residentes, no va a haber una "regeneración" sino que va a perder su "vida". En Corea, todavía hay una repulsión hacia el recuerdo de las tragedias históricas. El cambio en las actitudes hacia los barrios y de la imagen del barrio a sus habitantes son imprescindibles para establecer su identidad y promover la participación de la comunidad. Este cambio puede empezar con la incorporación de los barrios a la ciudad como un tipo de crecimiento que puede tener su propia lógica y transformación tanto en el pasado como en el futuro. Su complejidad es un resultado de óptimas soluciones de varios problemas; de sociedad, de recursos y de emplazamiento, etc. Por lo tanto, ya que los barrios de luna llevan funcionado más de medio siglo, debemos entender su orden o el código común que comparten sus residentes primero para dar una regeneración o una transformación sostenible.

\section{BIBLIOGRAFIA}

BUSQUETS I GRAU, J. (1999). La urbanización marginal. Barcelona: Edicions UPC

BUSQUETS I GRAU, J. y GOMEZ ORDOÑEZ, J. L. (1982). Plan Especial de Sant Josep en Sant Vicenç dels Horts de Barcelona, Rehabilitación de un barrio de Urbanización Marginal. CAU. Construcción Arquitectura y Urbanismo, 82, (34-62). Barcelona: Colegio Oficial de Aparejadores y Arquitectos Técnicos de Cataluña y Baleares

DE SOLÀ-MORALES, M. (1997). Las formas de crecimiento urbano. Barcelona: Edicions UPC

CAPEL, H. (2002). La morfología de las ciudades I. Sociedad, cultura y paisaje urbano. Barcelona: Ediciones del Serbal

VAN DEN BERG, L. et al. (1982). Urban Europe: A Study of Growth and Decline. Burlington: Pergamon Press PARK, R. E., BURGUESS, E. W. (1925) The City. Chicago: University of Chicago press

LEEDS, P. et al. (1999). Glasgow: The Forming of the City, Edinburgh: Edinburgh University Press

WALKER, D. (1982). The Architecture and Planning of MILTON KEYNES. Londres: Architectural Press

MILTON KEYNES DEVELOPMENT CORPORATION (1970). The Plan for Milton Keynes I

- (1970). The Plan for Milton Keynes II 
DAVIS, M. (2007). Planeta de ciudades miseria, Madrid: Foca, S.L.

TUNAS, D. (2008). The spatial economy in the urban informal settlement. Yakarta

BRILLEMBOURG, A., FEIREISS, K. y KLUMPNER, H. (2005) Informal City: Caracas Case. Munich: Prestel PIRES DO RIO CALDEIRA, T. (2007). Ciudad de Muros. Barcelona: Gedisa

SECCHI, B. (2015). la ciudad de los ricos y la ciudad de los pobres. Madrid: Catarata

MUNICIPIO DE BUSAN (1991). Historia de Busan 부산시사 III

INSTITUTO DE ESTUDIOS DEL DESARROLLO DE BUSAN 부산발전연구원 부산학 연구센터 (2008). Los barrios de Montaña de Busan, textos simbólico de lectura 부산의산동네, 부산을읽는상징적텍스트 (2010). Renacimiento de las carreteras de laderas de montaña 산복도로 르네상스

BAF부산국제건축문화제 ( 2010). Busan Space Forum 2010 부산공간포럼 종합자료집 